\title{
TÉCNICAS DIGITALES PARA LA ELABORACIÓN DE CALCOS DE ARTE RUPESTRE
}

\author{
DIGITAL IMAGE PROCESSING \\ APPLIED ROCK ART TRACING
}

\author{
IGNACIO MONTERO RUIZ (*) \\ ANGEL L. RODRÍGUEZ ALCALDE (**) \\ JUAN MANUEL VICENT GARCÍA $(*)$ \\ MARÍA CRUZ BERROCAL (*)
}

\section{RESUMEN}

La correcta documentación del arte rupestre ha sido una preocupación constante por parte de los investigadores. En el desarrollo de nuevas técnicas de registro, directas e indirectas, la fotografía ha ido adquiriendo mayor protagonismo. La imagen digital y su tratamiento permiten nuevas posibilidades de observación de las figuras representadas y, en consecuencia, una lectura mediante la realización de calcos indirectos de tanta o mayor fiabilidad que la observación directa. Este sistema evita los riesgos de deterioro que provocan los calcos directos. Se incluyen las bases matemáticas que sustentan el método.

\begin{abstract}
Adequate graphic recording has been one of the main objectives of rock art research. Photography has increased its role as a documentary technique. Now, digital image and its treatment allows new ways to observe the details of the figures and to develop a recording procedure which is as, or more, accurate than direct tracing. This technique also avoid deterioration of the rock paintings. The mathematical basis of this method is also presented.
\end{abstract}

(*) Departamento de Prehistoria. Centro de Estudios Históri$\cos$ (CSIC). Serrano, 13. 28001 Madrid. Correo electrónico: imontero@ceh.csic.es

(**) Departamento de Prehistoria. Facultad de Geografía e Historia. Universidad Complutense de Madrid. Ciudad Universitaria, s/n. 28040 Madrid. Correo electrónico: alra@fresno.csic.es

El artículo fue remitido en su versión final 23-IV-98
Palabras clave: Imagen Digital. Arte Rupestre. Documentación. Calcos. Pinturas.

Key words: Digital Image. Rock Art. Recording. Tracing. Paintings.

\section{INTRODUCCIÓN}

Este artículo presenta algunos de los resultados preliminares obtenidos en el curso de una de las líneas de investigación promovidas en torno al $\mathrm{Ar}$ chivo de Arte Rupestre del Departamento de Prehistoria del C.E.H. (CSIC) (en adelante AAR), y más concretamente de su más importante colección: el Corpus de Pintura Rupestre Levantina (en adelante CPRL). Las diversas acciones y líneas de investigación realizadas desde 1991 por un equipo formado por investigadores del CSIC y de la U.C.M. (1) y con financiación de la DGICYT (2) y

(1) Han sido muchas las personas que han formado parte o han colaborado en estas investigaciones. Se citan a continuación aquéllas que, además de los autores de este artículo, han tenido una vinculación directa con los proyectos de investigación y la conservación del AAR: $\mathrm{M}^{\mathrm{a}}$ Isabel Martínez Navarrete, Teresa Chapa Brunet, Almudena Hernando Gonzalo, César Heras, Aurora Garrido, Macario Anula Castells, Juan G. Leal Valladares, Myriam López Domínguez, Javier Goytre Samaniego, Concepción Martínez Murillo, Belén Sánchez Gómez, Raquel Vidal Calero, Laura Alcalá Zamora. La realización de las digitalizaciones y la asesoría técnica de los proyectos han corrido a cargo de José Latova.

(2) En dos proyectos: "Bases para la investigación del arte rupestre postpaleolítico en la Península Ibérica: el archivo de arte rupestre del Departamento de Prehistoria del CEH/CSIC" (pro- 
del CSIC, tienen como argumento común la exploración de las posibilidades ofrecidas por las técnicas de procesamiento digital de la imagen a la documentación, estudio y conservación de la pintura rupestre. El objetivo inicial era la creación de un banco de imágenes digitales a partir de los fondos fotográficos delAAR con el fin de asegurar su conservación, facilitar su explotación científica y favorecer su potencial para la difusión del conocimiento del arte rupestre. La experiencia acumulada ha permitido la progresiva incorporación de nuevas líneas de trabajo y objetivos generales.

Desde 1994, como consecuencia de la creación del Laboratorio de Proceso Digital de Imagen y Teledetección del Departamento de Prehistoria del C.E.H., las perspectivas de investigación y acción se han visto beneficiadas por la convergencia con la línea de investigación sobre aplicaciones de la Teledetección Espacial en Arqueología del Paisaje. Como resultado de esta convergencia, la transposición controlada de conceptos, métodos y técnicas procedentes del campo de la Teledetección al contexto de los estudios sobre Arte Rupestre se ha convertido en una de las líneas centrales de investigación. Sus propuestas generales han sido ya publicadas en estas mismas páginas (Vicent et alii, 1996).

Presentamos en este nuevo trabajo los desarrollos metodológicos derivados de una de las propuestas básicas de esta línea: la aplicación sistemática de la teoría y los métodos de clasificación de imágenes multibanda, que constituyen una de las herramientas básicas de la Teledetección, a la elaboración de "calcos electrónicos" de pinturas rupestres a partir de fotografías digitalizadas.

La Arqueología es, en general, una disciplina muy dependiente de la imagen (3), en un sentido amplio, como medio de fijar y comunicar el conocimiento. Pero, también en muchos casos, este conocimiento procede en gran parte de la observación visual de características de objetos o conjuntos de objetos. Es decir, que la creación de imágenes de objetos y contextos materiales formados por relaciones espaciales entre objetos es

yecto PB92-0088 de la DGICYT-CSIC, con vigencia de 1993 a 1996); y el actual, "Aplicaciones del proceso digital de imagen al estudio y conservación del arte rupestre prehistórico" (proyecto PB95-0227 de la DGICYT, en marcha desde 1996).

(3) Utilizaremos como definición de referencia del término imagen la primera de las acepciones que propone María Moliner (1992): "Figura de un objeto formada en un espejo, una pantalla, la retina del ojo, una placa fotográfica, etc., por los rayos de luz o de otra clase que parten del objeto". uno de los procesos observacionales básicos para la Arqueología.

Esto es especialmente cierto en el caso del arte rupestre. Sea cual sea la orientación desde la que se aborde, el objeto empírico de este estudio está constituido por imágenes. Desde un punto de vista físico, las técnicas pictóricas consisten en la manipulación intencional, por métodos físicoquímicos (aplicación de pigmentos), de la distribución espacial de las propiedades de reflexión de la luz visible de una superficie material, para inducir la creación de ciertas imágenes, los motivos pictóricos. Estas propiedades forman el sustrato físico de la percepción de imágenes, por lo que las definiremos como "imágenes de primer orden" o "imágenes fuente". Llamaremos "imágenes de segundo orden" a las inducidas por la imagen fuente en un sensor, sea éste natural, como la retina de un observador, o artificial, como una placa fotográfica (Fig. 1).

Considerado en sus rasgos más generales, el proceso normal de observación-interpretación consiste en la creación de imágenes de segundo orden a partir de las imágenes fuente (proceso de observación) y su análisis posterior (interpretación) que usualmente se resuelve en la producción de imágenes de tercer orden o imágenes interpretadas, en las que se representan los datos relevantes para el observador (por ejemplo, un calco).

Los especialistas en Arte Rupestre han sido conscientes desde el primer momento de la crucialidad de los métodos rigurosos para la transposición de las imágenes pictóricas a imágenes de segundo orden permanentes, susceptibles de servir de soporte documental a la interpretación fuera del contexto original. Esto excluye, obviamente, las imágenes visuales, es decir, las percibidas directamente por un observador humano, que por definición son efímeras. Más abajo discutiremos los procedimientos tradicionales para la verificación de este tipo de práctica observacional, la fotografía y el dibujo. Lo que interesa señalar ahora es que, independientemente del método usado para su creación, las imágenes de segundo orden se conciben, en general, como un medio de fijar permanentemente las características visuales de las pinturas rupestres de cara a su interpretación por medios igualmente visuales, y por tanto relativos a un observador singular. Esto significa que, al margen de la calidad y objetividad del método de generación de imágenes aplicado, el acto observacional sobre el que reposa la interpretación es sus-

T. P., 55, n. ${ }^{\circ} 1,1998$ 


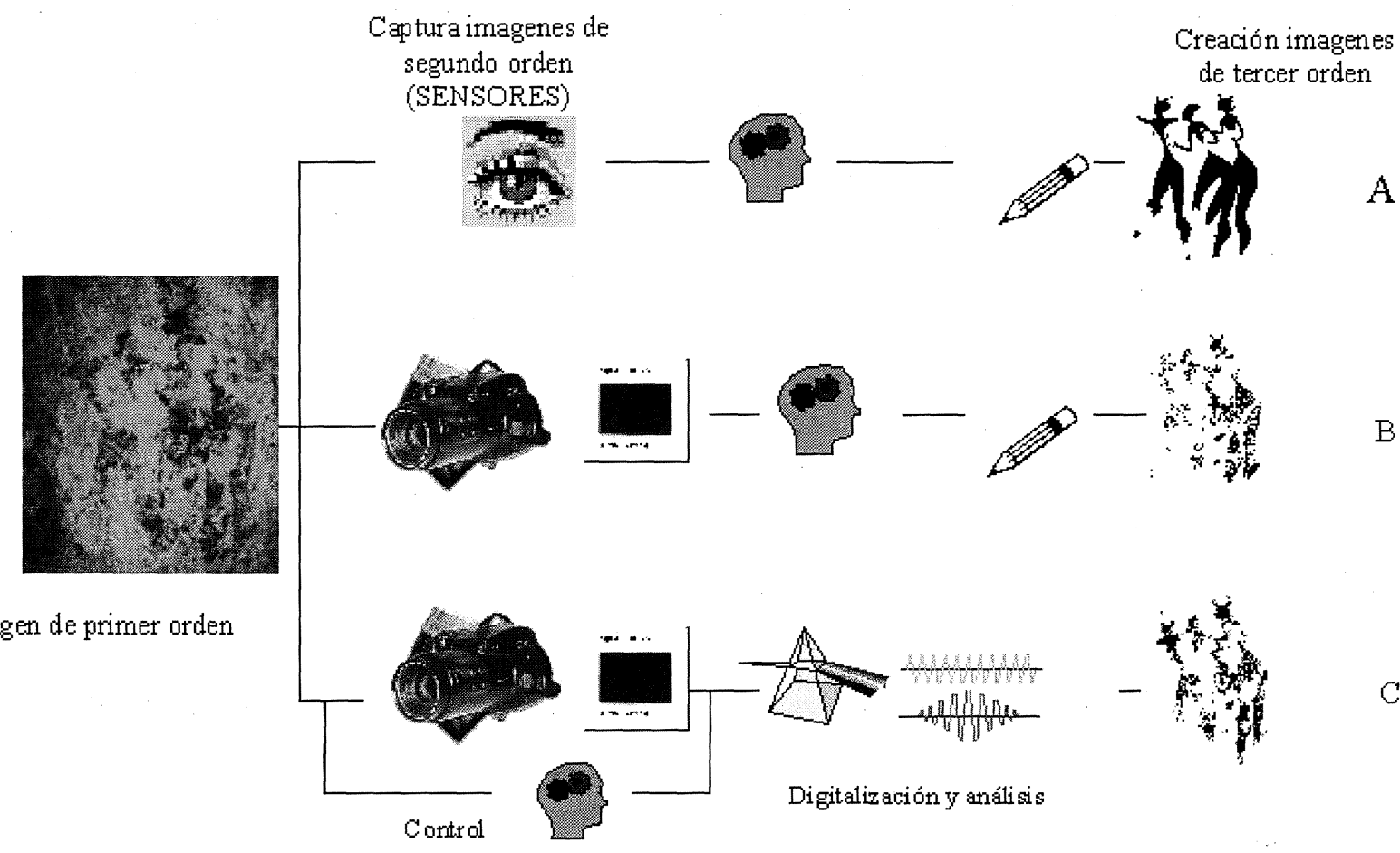

Fig. 1. Esquema de los procesos de obtención de imágenes de tercer orden: en A el ojo humano interviene como sensor y la experiencia y destreza del observador son cruciales en el resultado; en B el proceso es similar, pero se incorpora como sensor la fotografía, aunque todavía juega un papel determinante la interpretación del observador; en D el observador solo interviene como control para objetivar las condiciones del proceso de captura de imágenes de segundo orden que serán procesadas para obtener la imagen de tercer orden.

tancialmente subjetivo. En consecuencia, se reduce normalmente a la aprehensión de las características iconográficas atribuidas a la imagen de primer orden tal como quedan reflejadas en su análoga de segundo orden. Eventualmente, esta operación puede dar lugar a nuevas imágenes, de tercer orden que recogen los resultados de esta observación subjetiva.

Nótese que, como se ha dicho, las técnicas de dibujo aplicadas en la documentación no generan imágenes de segundo orden (es decir, análogos de la imagen fuente), sino que proceden de la interpretación visual del observador, y son por lo tanto imágenes de tercer orden subjetivizadas (lo cual no implica que no sean aceptablemente fieles al original). Pero, aún en el caso del uso de imágenes fotográficas, que se pueden considerar "objetivas" en la medida en que las condiciones de su producción haya sido controladas, el proceso interpretativo tradicional se resuelve de nuevo en una percepción visual subjetiva. Es decir, el investigador no puede hacer otra cosa, en última instancia, que mirar las fotografías y actuar como actuaría ante los originales, tratando de identificar visualmente los contornos de los motivos, apreciar la variabilidad de los pigmentos, etc. Por lo tanto, independientemente de las posibilidades que ofrecen las técnicas fotográficas de objetivizar el proceso de observación, la subjetividad de los procedimientos visuales se desliza inevitablemente en la producción de imágenes interpretadas, comprometiendo el valor científico de la totalidad del proceso de observación-interpretación.

El alcance de las técnicas de procesamiento digital de imágenes es, precisamente, que permiten romper este confinamiento subjetivo de los procesos observacionales basados en la fotografía, al permitir la matematización de la producción de imágenes de tercer orden. En efecto, la digitalización de fotografías tomadas bajo condiciones controladas permite la utilización de éstas no ya como meros análogos visuales de una imagen real, sino como matrices de datos cuantitativos ordenados espacialmente que recogen la variabilidad de de- 
terminadas propiedades físicas relevantes de la superficie objeto de observación (por ejemplo, la distribución y variabilidad de los pigmentos), y hacer accesible esta variabilidad a métodos de análisis cuantitativo. Dicho en otros términos, la combinación de técnicas fotográficas rigurosamente controladas y técnicas de proceso digital de imagen permite hacer de la fotografía una técnica de observación y medida en el sentido más estricto de estos términos en el vocabulario metodológico general.

De esta manera, los distintos problemas interpretativos que plantea la documentación de la pintura rupestre pueden formalizarse a partir de modelos matemáticos e instrumentarse en la práctica como procesos experimentales controlados. Así, por ejemplo, en el caso que presentamos en el presente trabajo, la elaboración de calcos, el problema básico consiste en la transformación de una matriz de valores continuos de color en una matriz dicotómica en la que sólo figuran dos valores: "pigmento" y "soporte" (aunque, como veremos, el modelo se puede enriquecer considerablemente). Esta matriz dicotómica puede representarse analógicamente y tendrá el mismo aspecto que un calco tradicional. Sin embargo, no será ya el producto de la destreza de un observador entrenado en el reconocimiento visual de los motivos pictóricos y falible, sino la solución a un problema estándard de clasificación estadística. Los resultados dependerán evidentemente de varias decisiones, en cuanto al modelo matemático elegido y sus parámetros, los umbrales de asignación de valores a categorías interpretativas, y los distintos procesos técnicos implicados (producción de imágenes fotográficas y digitalización de las mismas). Pero todas estas decisiones pueden consignarse y modificarse de forma intersubjetivamente contrastable, configurando un auténtico proceso experimental.

Damos a conocer aquí algunos resultados obtenidos de la aplicación sistemática de estos principios a fotografías procedentes del CPRL, que pueden servir como ejemplo de la potencial utilidad del enfoque. Ahora bien, se trata de fotografías procedentes de un fondo histórico documental, creado entre 1971 y 1975 bajo la orientación de los criterios documentales entonces vigentes. $\mathrm{Ca}$ recemos, por lo tanto, de parte de la información que sería necesaria para una aplicación exhaustiva del método, que, como se ha dicho, incluye un enfoque experimental riguroso de la producción de imágenes de segundo orden. Sin embargo, creemos que los resultados justifican el interés del experimento, en la medida en la que se demostrará que las propuestas técnicas de generación de calcos electrónicos pueden aplicarse con éxito a este tipo de documentos que constituyen la mayor parte del registro fotográfico acumulado hasta la fecha sobre el arte rupestre prehistórico.

Revisaremos, en primer lugar, la historia de los procedimientos de documentación aplicados en el caso de la investigación sobre la pintura rupestre levantina, para exponer a continuación las generalidades de un método de clasificación aplicable al caso y, finalmente, mostrar algunos resultados preliminares.

\section{ASPECTOS DE REGISTRO DEL ARTE RUPESTRE LEVANTINO}

Desde los primeros descubrimientos realizados por Cabré en 1903, y de manera paralela al arte rupestre paleolítico, una de las principales preocupaciones de los investigadores ha sido la reproducción fiable y con calidad de las pinturas y grabados prehistóricos. Esta preocupación se detecta en los comentarios que se incluyen en los primeros artículos y monografías, donde se manifiesta la necesidad de expresar que el trabajo se había realizado con precisión y objetividad.

La interpretación de las figuras, discutida y en algunos casos discutible, pasaba por una correcta observación de lo pintado, pero el estado de deterioro y la pérdida de parte del pigmento, frecuente en la pintura al aire libre, conducía casi inevitablemente a la reconstrucción idealizada de las figuras. La percepción visual de las pinturas necesitaba con frecuencia, como así reconocen los autores, del humedecimiento más o menos intenso de las mismas, y los cambios en la luz natural, según el momento del día y del año, influían también en la apreciación final. Así, por ejemplo, Obermaier y Wernert (1919: 16), aunque definían sus intenciones en el trabajo del Barranco de la Valltorta:

"Ha sido nuestro particular empeño, y hemos insistido, en reproducir las figuras con una fidelidad absoluta, tal y como se presentan actualmente al observador libre de ideas preconcebidas. Por lo tanto, nos hemos abstenido severamente de influir, cediendo a cualquier interpretación subjetiva, sobre las copias, sea

T. P., 55, n. ${ }^{\circ} 1,1998$ 
idealizando un tanto los dibujos, sea restaurándolos",

sin embargo, apenas un par de párrafos después aclaraban que:

"trozos desvanecidos, de contornos inseguros, están reproducidos, como en los originales, en color claro y sin limitación fija de líneas... En donde parecía indicado (para la mejor comprensión de los dibujos defectuosos) el reconstituir fragmentos desaparecidos, se procedió a ello, indicándolo por series sencillas de puntos".

Hernández Pacheco (1924: 178) daba gran importancia al método seguido en la realización de la copia para reducir las interpretaciones discrepantes y/o dudosas. Este autor criticaba el procedimiento de calcos de línea en papel transparente seguido por sus colegas, calcos que posteriormente eran rehechos en el laboratorio sin tener presente el original, apoyándose únicamente en las indicaciones anotadas. Insistía en la necesidad de una buena identificación previa al calcado por transparencia, basada en una observación detallada. El calco era inmediatamente reproducido en papel, con la figura delante para captar todos los detalles. Sin embargo, tampoco escapa a presentar la reconstrucción de algunas figuras.

El calcado directo fue y ha sido, sin duda, el principal sistema seguido hasta nuestros días, y sustituyó bien pronto al croquis o dibujo a mano alzada, utilizado en aquellos casos en los que el soporte resultaba frágil y la presión del calco podía dañarlo (Moneva, 1993: 415-419). El deterioro que este sistema de calco directo producía en las pinturas no fue percibido o valorado por todos los investigadores, y aunque hubo algunas llamadas de atención (Moneva, 1993: 430), se realizaron actuaciones descabelladas, como el perfilado a lápiz de las figuras en el Barranco de la Valltorta. El humedecimiento de las pinturas, práctica habitual hasta la actualidad, no era considerado perjudicial por Obermaier yWernert (1919: 16). Hoy día esta práctica es condenada y reprobada por los especialistas, $\mathrm{y}$, en general, se considera perjudicial cualquier contacto con la pintura y el soporte (Beltrán, 1981).

Debido al sistema de reproducción en los primeros años de investigación, las discrepancias en la interpretación de figuras son notorias, con opiniones enfrentadas entre autores. Esas diferencias, que afectan principalmente a representaciones incompletas o manchas de color a las que necesariamente se quiere otorgar un significado (4), se aprecian también en los detalles de figuras bien identificadas, como las que se reproducen en la figura 2 , y que indican el grado de variación y precisión de esos calcos.

La fotografía tardó en aceptarse como método fiable, y aún así muchas veces como un documento complementario del calco directo (Vertut, 1981). Como señalan Aujoulat (1987) y Moneva (1993), la baja calidad y contraste de las primeras fotografías, y una cierta complejidad de ejecución, no permitían confiar en ellas y, además, la utilización del blanco y negro limitaba el registro de todos los matices de color. En una primera época la fotografía se utilizó, tal y como aparece en las publicaciones, para mostrar el espacio físico en el que se encontraban estas representaciones, y muy esporádicamente se dedicaron a las propias pinturas. Sin embargo, hubo intentos de reconstruir figuras a partir de fotografías en los llamados croquis de lectura (Moneva, 1993: 436). Ejemplos de este uso en el arte levantino los encontramos en dos láminas publicadas en la monografía de la Cueva de La Araña (Hernández Pacheco, 1924: lám. XVII y XVIII), una de ellas la famosa escena de la recolección de la miel.

La mejora técnica de la fotografía en color, la aparición de la diapositiva y el formato de 35 $\mathrm{mm}$., la macrofotografía, o las películas de infrarrojo y ultravioleta han ido concediendo un mayor protagonismo al empleo documental de la fotografía, aunque el uso de los últimos tipos de películas no ha conseguido todavía generalizarse, quizás por necesitar una mayor especialización para su correcta utilización. Lo mismo puede decirse de la fotogrametría, aplicada en la reproducción tridimensional de las principales cuevas, como Altamira (Llanos y García, 1981) o Lascaux (Aujoulat, 1987). La especialización en su ejecución y su elevado coste en relación a la fotografía convencional han mantenido su uso bastante restringido (5). La fotogrametría permite definir con preci-

(4) Puede servir de ejemplo la crítica de Hernández Pacheco (1919: 416) a la identificación por parte de Obermaier y Wernert (1919: 61) de un pato en la Cueva de Cavalls, figura hoy día desaparecida para poder pronunciarse de manera independiente, o de un onagro de la Cueva del Civil, ambas en el Barranco de la Valltorta. No hay que olvidar que el tipo de fauna identificada está en relación directa con la cronología que se otorga a este arte. Cabré y Porcar fueron también ampliamente criticados por la falta de fiabilidad de sus reproducciones.

(5) En la actualidad los sistemas son mucho más accesibles, los equipos y la reconstrucción con ordenadores facilita su empleo y probablemente en los próximos años se incrementará su aplicación, como por ejemplo en el reciente trabajo de Bell y otros (1996) sobre la Cueva de El Ratón, en la Baja California. 


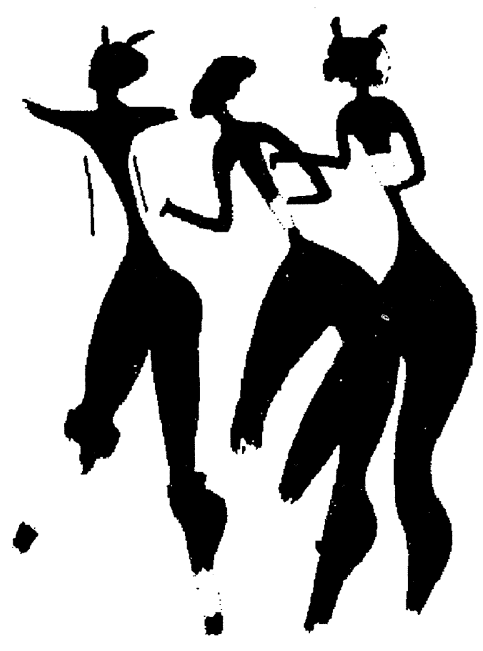

Duran, 1915-1920

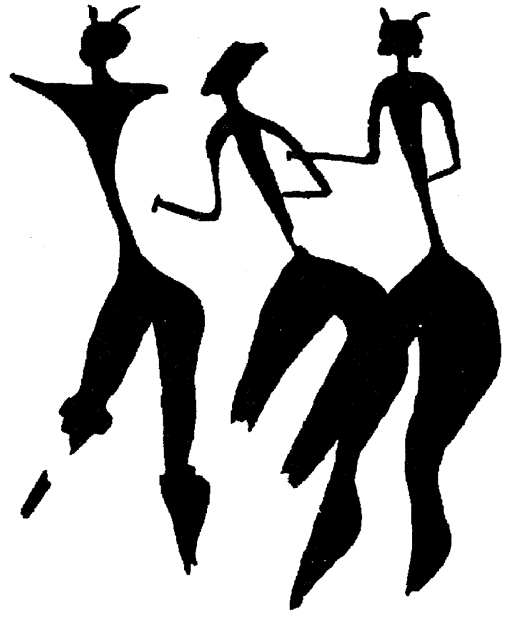

Kuhn, 1926

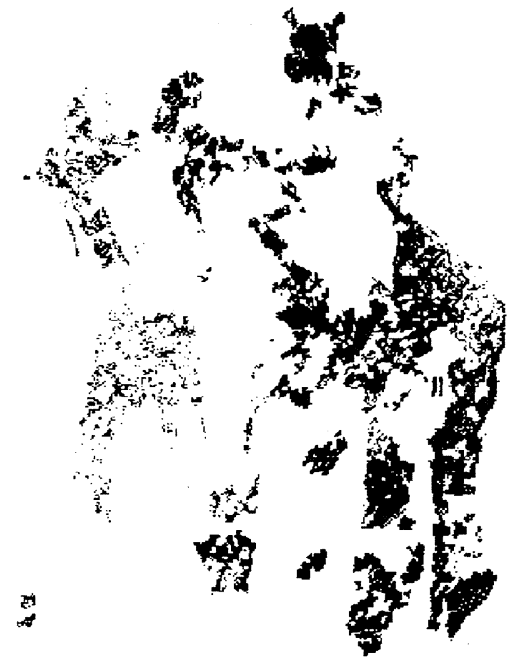

Viñas, 1982

Fig. 2. Diferencias en interpretación de figuras y publicación de calcos: “(...) grup de tres figures humanes (...)” según Duran i Sanpere (1915-1920); "tres figuras humanas -posiblemente mujeres- (...)", según Kuhn (1926); "grupo de figuras humanas estilizadas (...) La composición comprende tres hombres pintados en color negro (...)" según Viñas (1982). En las dos primeras se aprecia la reconstrucción de algunas partes, así como la estilización en el trazo de las figuras.

sión la forma, dimensiones y posición en el espacio de un objeto, partiendo de medidas realizadas sobre fotografías del mismo, pero su coste es mayor que la fotografía convencional.

El calco indirecto a partir de la fotografía ha sido aplicado con relativa frecuencia. Un reconocimiento explícito de su uso se encuentra en los estudios de arte rupestre nubio (Almagro Basch y Almagro Gorbea, 1968: 29), justificando su empleo como alternativa a la rapidez con la que debió efectuarse la documentación. Se menciona también su empleo con buenos resultados en el arte rupestre levantino y sahariano, generalmente como método de comprobación y corrector de los calcos directos originales.

En ocasiones, se combinaba el calco en papel transparente y su posterior traslado a papel vegetal con la proyección del cliché sobre pantalla transparente para comprobar y confirmar los datos originales. También se empleó el sistema de proyección de la foto para realizar copias a escala más reducida que el original, con la finalidad de facilitar su reproducción impresa.

Beltrán recomendaba (1981: 136) el empleo complementario y combinado de los tres sistemas de registro: dibujo a mano alzada, calco y fotografía. Sin embargo, admitía la subjetividad del sistema al comentar que las comprobaciones sucesivas exigían siempre rectificaciones. A pesar de la combinación de técnicas, los resultados no siempre resultaban plenamente satisfactorios, especialmente en paneles complejos con abundantes figuras y superposiciones, como reconocen $\mathrm{Ca}$ rrasco y Pastor (1981: 169-170).

Sin embargo, aunque el método indirecto sea práctico y menos agresivo con las pinturas, existe una desconfianza bastante generalizada a apoyarse en él y prescindir del sistema de calco por observación directa (6). De manera explícita expone Loubser (1997: 14) este rechazo: un registro adecuado pasa por una observación intensiva de la superficie rocosa y del pigmento de manera directa la dependencia exclusiva en la fotografía es inadecuada ya que ésta no es capaz de capturar los detalles del pigmento y las irregularidades del soporte. Según este autor, el calco se ha mostrado más efectivo que la fotografía como sistema de registro. Y quizás hasta la fecha tenga razón en esa afirmación, pero ahora la nueva tecnología digital permite otras posibilidades de observación que hacen al calco electrónico al menos tan efectivo

(6) Para evitar el contacto con las pinturas se ha desarrollado un método indirecto mediante bastidores que sujetan el papel transparente a una pequeña distancia de la pintura. Su uso se complica dependiendo del relieve de la roca (Sanchidrián, 1987: 123-24) aunque permite obtener sistemas de proyección diferentes (Aujoulat, 1987: 50-51). 

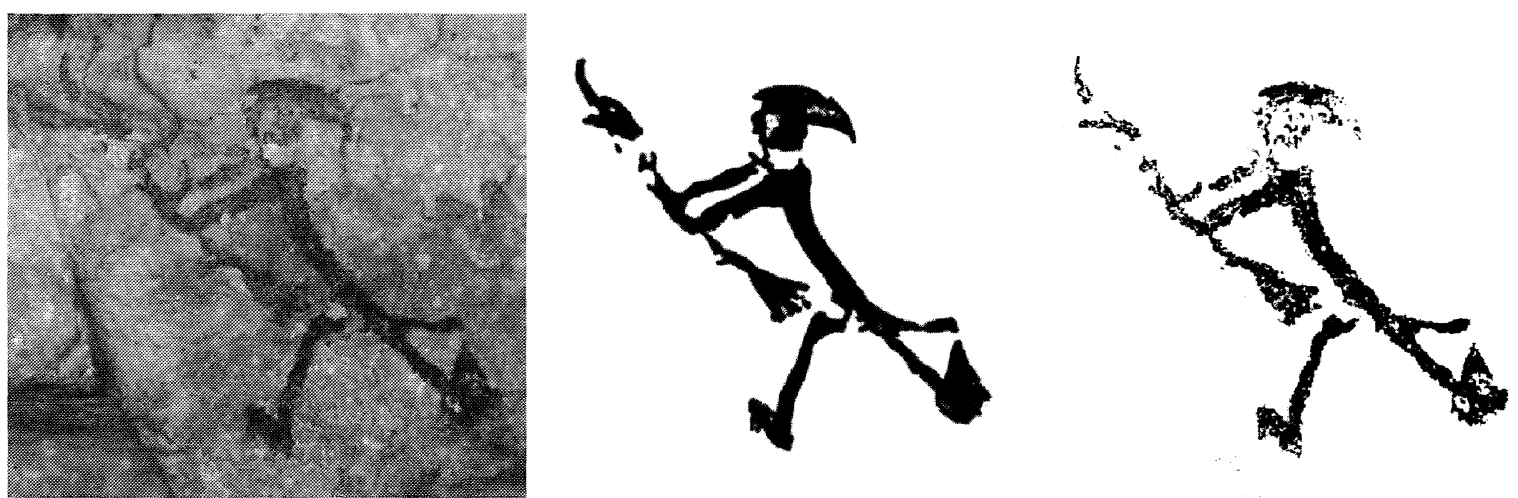

Fig. 3. a) Arquero en marcha a la izquierda. Figura 12 (Abrigo V), Cingle de la Gasulla, Barranco de la Gasulla, Ares del Maestre, Castellón. Tamaño 4 cms. Fotografía tomada en junio de 1971 (CPRL del Departamento de Prehistoria del C.E.H.). b) Fotocalco realizado por Gil Carlés a la misma figura mediante técnica de revelado químico. c) Calco electrónico de la misma figura realizado en el Departamento de Prehistoria del C.E.H. a partir de la imagen digital en alta resolución.

como el calco realizado en el campo, y tiene algunas otras ventajas. Sin olvidar que la fotografía en longitudes de onda fuera del espectro visible aporta perspectivas que nunca se conseguirán por mucho que se incremente el trabajo de observación visual.

\section{EL CALCO ELECTRÓNICO}

La propuesta de calco electrónico debe entenderse como una herramienta a disposición del investigador que permite analizar de una manera más fiable y objetivable la información representada, así como procesar otros datos que visualmente son difíciles e incluso imposibles de captar por el ojo humano. Depende de la calidad de la fotografía con la que se trabaja el conseguir un mayor o menor rendimiento del sistema, pero incluso imágenes aparentemente poco contrastadas poseen un alto valor informativo.

Una imagen digital está compuesta por matrices numéricas en las que se representan las diversas variables del color (tono, saturación, brillo), cuya combinación proporciona millones de posibilidades. Aislar cada una de ellas de forma individualizada, así como realizar selecciones combinadas con diversos criterios nos permite, ante todo, observar esa imagen de maneras muy diferentes. Se trata de descomponer la imagen y clasificar su información para, de manera selectiva, con criterios matemáticos, discriminar la información relevante, en este caso la disposición en el espacio del pigmento.
Hay que destacar que la opción de tratamiento de imagen que proponemos no entra dentro del concepto artístico de retoque fotográfico, aunque puedan usarse algunas de las opciones de trabajo que ofrecen ese tipo de programas informáticos (7). No hay manipulación de la imagen, ni falseamiento de la información real (8). Unicamente se procede al análisis de las variables descompuestas, siguiendo criterios matemáticos para procesar los miles de píxeles que componen cada imagen. La clasificación de esos grupos de información en los elementos presentes, como pigmento, roca base, zonas de sombra, grietas, desconchados, $\mathrm{L}_{\text {. }}$. medades, costras, etc., posibilita representar cada una de ellas por separado.

Nuestra atención se fija por tanto en el pigmento y la forma que éste adopta. Con ello logramos identificar el objeto representado tal y como ha sido el objetivo de los calcos realizados hasta la fecha por otros métodos y generamos una imagen de tercer orden. También es posible discriminar tonos de pigmento y representar de modo diferenciado esas variaciones, tanto en color como en escala de grises, de una manera más rápida y cómoda que en los sistemas de revelado químico diferencial, como el utilizado de manera experimental por Gil Carles en el CPRL, bajo la denominación de fotocalco (Fig. 3), o el sistema de equidensidades que propusiera Aujoulat (1987: 92-97). En la figura 4

(7) Criterios de retoque fotográfico como mejorado y contraste pueden ser útiles para eliminar información ruidosa, del mismo modo que los filtros.

(8) Existen ejemplos de manipulación de fotografías (Beltrán, 1981: 136; Moneva, 1993: 436). 


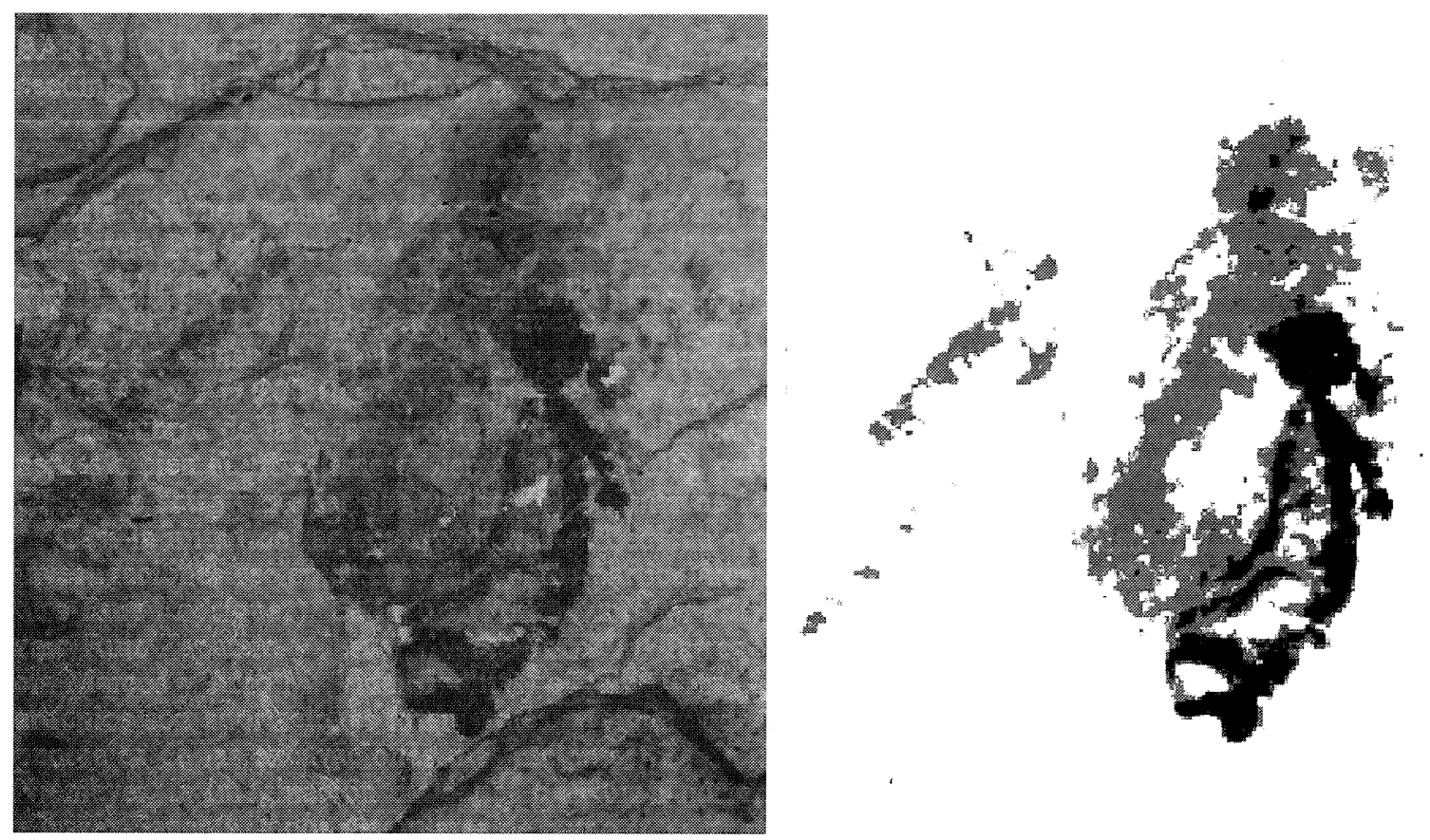

Fig. 4. Fotografía y calco electrónico de la figura 32 (Abrigo IV), Cingle de la Gasulla, Barranco de la Gasulla, Ares del Maestre, Castellón. Tamaño 5,5 cms. Fotografía tomada en junio de 1971. (CPRL del Departamento de Prehistoria del C.E.H.). Identificada como "mancha, posiblemente de tipo antropomorfo", aunque en realidad muestra una superposición de dos figuras humanas.

se representa de modo sencillo la superposición de dos personajes humanos, otorgando un tono de gris diferente a cada uno de ellos, a partir de una imagen digital de $1.024 \times 1.536$ píxeles.

El ojo humano es un sensor de alta capacidad. Sin embargo, está sometido a efectos visuales engañosos que limitan la fiabilidad de su percepción y la hacen dependiente de cada sujeto. Así, un color, bajo condiciones fijas de iluminación, puede mostrar diferente gama según los colores colindantes: es lo que se denomina contraste simultáneo. Nuestros ojos, además de adaptarse a las diferentes claridades de luz, también se adaptan al color de dichas claridades, al tiempo que generan un proceso de conversión cromática, por el cual un tono de color es percibido de manera distinta en un primer instante que después de transcurrido un tiempo. Por tanto, el contraste simultáneo demuestra que no existe ninguna relación fija entre el estímulo del color y la sensación resultante. El ojo realiza esos procesos de corrección autónomamente y tiende a situarse en un nivel de sensibilidad intermedio (Moreno, 1996: 13-25). Finalmente, nuestra percepción visual es una imagen integrada, en la que todas las variables se superpo- nen ofreciéndonos una única perspectiva. Ésta cambiará al cambiar la iluminación o el punto de vista, pero no tenemos capacidad de filtrar y descomponer la información que nos llega.

La fotografía también fija un momento de percepción de la imagen, pero podemos fotografiar incluso en condiciones diferentes, seleccionando aquellas variables de color que deseemos, e incluso captando longitudes de onda no visibles. Nos ofrece un abanico mayor de percepción de la realidad. Estas fotos pueden ser visualizadas directamente por los ojos del investigador, o multiplicar la observación, y por tanto la información que contienen, a través de un análisis digital.

El riesgo inherente de la fotografía es la reproducción fiable de las gamas de color de cada parte de la imagen. El revelado químico puede alterar los verdaderos tonos y deformar o distorsionar esta realidad. En el proceso de digitalización se producen también ditorsiones cromáticas. Sin embargo, la fotografía digital puede corregir esas desviaciones y restituir las condiciones originales. La inclusión de una escala de color permite realizar con éxito esas tareas (Bednarik y Seshadri, 1995) de calibrado. 

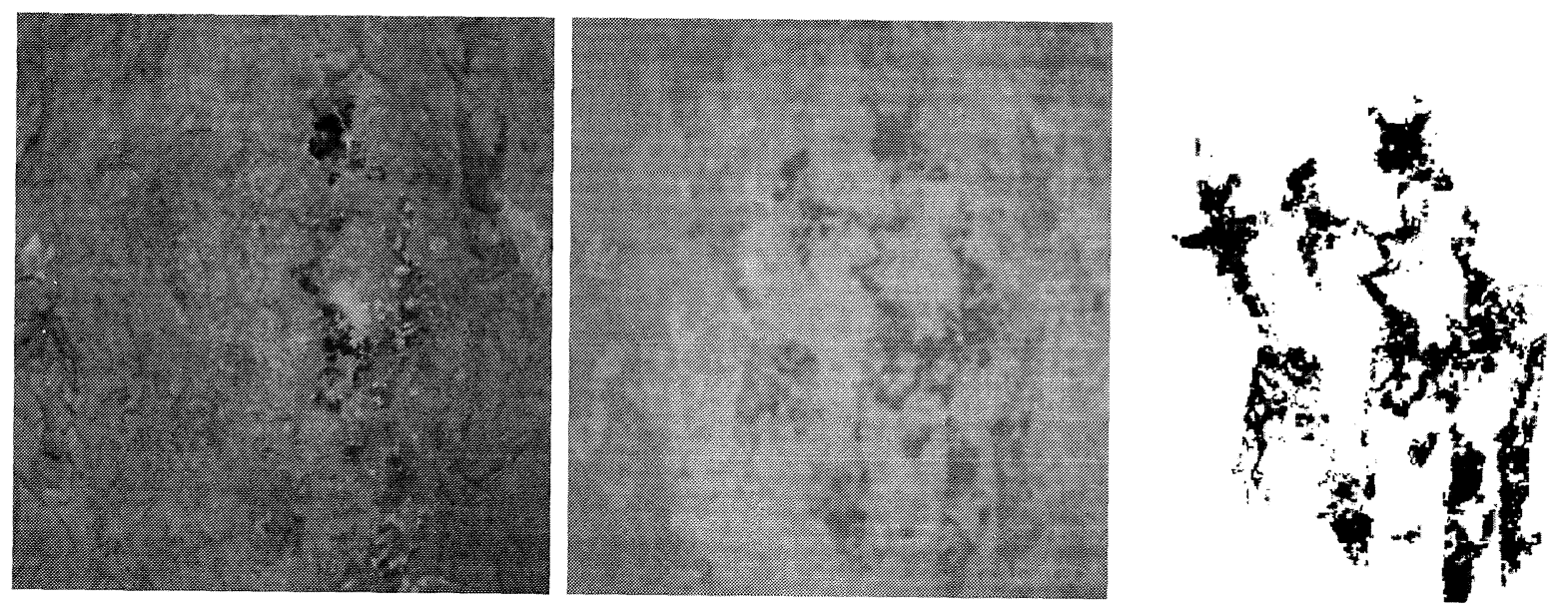

Fig. 5. a) fotografía con restos de tres figuras humanas a la izquierda. Figuras 2 a 4 (Abrigo IX), Abrigos de la Saltadora, Barranco de la Valltorta, Cuevas de Vinromá, Castellón. Tamaño 23,5 cms. Fotografía tomada en octubre de 1973 (CPRL del Departamento de Prehistoria del C.E.H.). b) Descomposición y filtrado de la imagen digital para resaltar las pinturas. c) Calco electrónico realizado a partir de la imagen digital a alta resolución.

Finalmente, como limitación de la fotografía en formato digital hay que indicar que ésta constituye una imagen discreta, es decir, no continua, por lo que la información que abarca cada unidad mínima establecida (píxel) debe tomar valores medios de la zona representada. La resolución de la imagen se convierte en factor clave de la fiabilidad de la misma. Nuestra experiencia nos indica que una resolución media $(512 \times 768$ píxels $)$ no es suficiente para un adecuado tratamiento de la imagen (incluso en el modo simplificado) y sólo a partir de resoluciones como $1.024 \times 1.536$ píxeles empiezan a obtenerse resultados satisfactorios.

Nuestro trabajo con las fotos del AAR desde 1992 (Vicent, 1994) nos permite afirmar que, sin controles exhaustivos sobre la imagen fotográfica digitalizada, el rendimiento informativo obtenido es adecuado, y se generan calcos fiables y precisos, tal y como hemos presentado en ocasiones anteriores (9) o en los ejemplos aquí publicados (Fig. 3, 4 y 5), tratados matemáticamente.

A partir del uso de simples técnicas de mejora y contraste o de selección manual de los valores que representan al pigmento pueden conseguirse también, de manera simplificada, resultados aceptables, pero a veces los problemas de discriminación

(9) Presentaciones del trabajo realizado con el CPRL en las que se incluyeron calcos electrónicos se realizaron en el First Meeting of the European Association of Archaeologists (Santiago de Compostela, 1995) y en el Salón Internacional del Patrimonio Cultural (SIPAC) (Santiago de Compostela, 1997). entre soporte y pigmento son mayores (Castelo Branco, 1997). En los casos en que el soporte sea de tono rojizo, como en una gran parte de la pintura levantina, es necesario un mayor número de toma de decisiones por parte del operador. La limitación en la discriminación de tonos se produce también en el método utilizado por la Universidad de Cantabria, en cuya propuesta de obtención automática de calcos se indica que es aplicable únicamente a pinturas negras sobre soportes claros.

Estos métodos que emplean programas de retoque fotográfico pueden refinarse aún más, ya que disponen de suficientes herramientas automatizadas para ello y permiten la creación de otras específicas. Nuestra propuesta de clasificación de la imagen obtiene además un análisis más detallado en su lectura, y no sólo del pigmento, que ayuda a una interpretación más correcta, eliminando falsas impresiones visuales que grietas y sombras generan y que con los procedimientos anteriores no son filtrados.

\section{CLASIFICACIÓN DE IMÁGENES MULTIESPECTRALES}

El proceso de clasificación de una imagen trata de hacer interpretables los valores numéricos de la matriz que conforma, de modo que pueda cualificarse la imagen a partir de sus características diferenciales. A continuación se expone brevemen- 
te una introducción a las bases fundamentales de los procedimientos de clasificación automática de imágenes; por ello, únicamente discutiremos cuestiones sobre la teoría de la decisión y la distribución normal multivariante.

La utilización de técnicas de clasificación en el análisis y realización de calcos digitales, o imágenes de tercer orden (Fig. 1, opción C), es una tarea compleja, fundamentalmente porque implica, primero, la generalización del uso de imágenes digitales, segundo, la adecuación de principios y prácticas desarrollados en teledetección espacial y, finalmente, la conceptualización de la imagen discreta como una matriz operable y aprehensible desde los parámetros de la teoría de la decisión.

En principio podemos decir que el objetivo de la clasificación de una imagen es hacer interpretables los valores numéricos obtenidos por el sensor (en este caso doblemente filtrado, por la cámara óptica y el sensor electrónico o escáner).

El planteamiento del problema se reduce a establecer si una celdilla (un píxel, en nuestro caso) pertenece a una u otra clase de información de los posibles estados relacionados en la leyenda; esto es, se trata de definir si un píxel que presenta un cierto nivel digital es pigmento en tal o cual estado de conservación, una costra calcárea o soporte de una u otra composición.

Hemos de insistir en que, cuando hablamos de clasificación de imágenes, no lo estamos haciendo de retoque fotográfico o de operaciones de realce; esto último no es más que una transformación de la imagen original que permite una mejor visualización y, en definitiva, facilita la interpretación por parte del analista. La interpretación es una tarea del intérprete; mientras que en la clasificación, es el ordenador el que, mediante una cuantificación, distribuye las clases de las unidades elementales contenidas en la imagen.

La clasificación de imágenes es esencialmente un proceso de toma de decisiones con datos que presentan una considerable variabilidad estadística. Por ello, hemos de considerar las soluciones que proporciona, al respecto, la teoría estadística de la decisión (Ormeño, 1993: 178). Desde esta perspectiva, el proceso de asignación de un píxel a una clase lleva asociado una probabilidad de error estadístico, de modo que se necesita minimizar algún criterio de error en la superficie a clasificar, para lo cual se toman en consideración pequeños grupos de píxeles de los que se conoce la clase a la que pertenecen.
Entre las teorías clásicas utilizadas en teledetección espacial, hemos elegido la clasificación de máxima verosimilitud o bayesiana óptima. Trataremos de explicar brevemente en qué consiste este método, puesto que es la base de nuestra clasificación y, por tanto, de los resultados de la interpretación.

Imaginemos que tenemos una imagen monobanda en la que sólo existen dos clases (pigmento y soporte); si existe la misma cantidad de una que de otra, entonces, un píxel tiene la misma probabilidad de ser pigmento que soporte. Generalizando, podemos decir que existe una probabilidad a prio$r i$ de que un elemento de la imagen pertenezca a la clase figura (que llamaremos $\mathrm{P}\left(\mathrm{w}_{1}\right)$ ) o de que pertenezca al soporte $\left(\mathrm{P}\left(\mathrm{w}_{2}\right)\right)$. Con nuestra hipótesis de partida, ambas son positivas y suman 1 . Si únicamente tenemos estas probabilidades para asignar un píxel, obviamente, elegiremos la más probable; no obstante, para tomar una decisión contamos con más información: el valor digital $(x)$.

Debido a que diferentes tipos de pigmento tienen diferentes niveles digitales, podemos considerar a $x$ como una variable aleatoria continua cuya distribución es dependiente del estado. Si llamamos a $\mathrm{p}\left(\mathrm{x} / \mathrm{w}_{\mathrm{j}}\right)$ función de densidad de probabilidad de $x$ cuando el estado es $\mathrm{w}_{\mathrm{j}}$, la diferencia $\mathrm{p}\left(\mathrm{x} / \mathrm{w}_{1}\right)-\mathrm{p}\left(\mathrm{x} / \mathrm{w}_{2}\right)$ describe la separación entre pigmento y soporte.

Si conocemos la probabilidad a priori $\mathrm{P}\left(\mathrm{w}_{\mathrm{j}}\right)$ y las funciones de densidad $\mathrm{p}\left(\mathrm{x} / \mathrm{w}_{\mathrm{i}}\right)$, conocemos el valor digital de un píxel: $x$. Esta medida afecta a la asignación del píxel; el Teorema de Bayes nos proporciona el modo de hacerlo.

$$
\mathrm{P}\left(\mathrm{w}_{\mathrm{j}} / \mathrm{x}\right)=\mathrm{p}\left(\mathrm{x} / \mathrm{w}_{\mathrm{j}}\right) \mathrm{P}\left(\mathrm{w}_{\mathrm{j}}\right) / \mathrm{p}(\mathrm{x})
$$

donde

$$
p(x)=\sum_{1}^{2} p\left(x / w_{j}\right) P\left(w_{j}\right)
$$

Esto nos muestra la forma en que el valor de $x$ transforma la probabilidad a priori $\mathrm{P}\left(\mathrm{w}_{\mathrm{j}}\right)$ por una probabilidad a posteriori $\mathrm{P}\left(\mathrm{w}_{\mathrm{i}} / \mathrm{x}\right)$.

Como tenemos que minimizar la probabilidad de error, podemos plantear el siguiente teorema bayesiano de decisión (Peña, 1986: 73): decidiremos $\mathrm{w}_{1}$ si $\mathrm{P}\left(\mathrm{w}_{1} / \mathrm{x}\right)>\mathrm{P}\left(\mathrm{w}_{2} / \mathrm{x}\right)$, si no, decidire$\operatorname{mos} \mathrm{w}_{2}$.

Ésta es básicamente la idea. Si generalizamos a una imagen multibanda, el valor digital de un píxel está determinado por los valores digitales del mismo en todas las bandas, de modo que el es- 
calar $x$ ahora es un vector $(\vec{x})$ : el vector de características. Además, si en lugar de dos posibles estados, consideramos un conjunto finito de ellos $\Omega=$ $\left\{w_{1}, w_{2}, \ldots, w_{s}\right\}$, el Teorema de Bayes se formalizaría del siguiente modo

$$
\begin{aligned}
& P\left(w_{j} / \vec{x}\right)=p\left(\vec{x} / w_{j}\right) P\left(w_{j}\right) / p \overrightarrow{(\vec{x})} \\
& p \overrightarrow{(\vec{x})}=\sum_{1}^{s} p\left(\vec{x} / w_{j}\right) P\left(w_{j}\right)
\end{aligned}
$$

de donde se obtiene el siguiente teorema bayesiano de la decisión

$$
\text { Decidir } \mathrm{w}_{\mathrm{i}} \text { si } \mathrm{P}\left(\mathrm{w}_{\mathrm{i}} / \overrightarrow{x)}>\mathrm{P}\left(\mathrm{w}_{\mathrm{j}} / \overrightarrow{x)} \quad \forall \mathrm{j} \neq \mathrm{i}\right.\right.
$$

La distribución de los niveles digitales dentro de cada una de las bandas de una imagen se puede asimilar a una distribución normal. Si la imagen es multiespectral hablaremos de una distribución normal multivariante. La función de densidad univariante de la distribución normal es

$$
\begin{gathered}
f(x)=\frac{1}{\sigma \sqrt{2 \pi}} \exp \left[-\frac{1}{2 \sigma^{2}}(x-\mu)^{2}\right] \\
-\infty<x<\infty
\end{gathered}
$$

donde $\mu$ es la media y $\sigma$ la desviación típica.

En un espacio multidimensional, sería

$$
f(\vec{x})=\frac{1}{|\Sigma|^{1 / 2}(2 \pi)^{n / 2}} \exp -\frac{1}{2}(\vec{x}-\vec{M})^{t} \Sigma_{\rightarrow}^{-1}(\vec{x}-\vec{M})
$$

donde $\vec{x}$ es el vector de características, $\vec{M}$ el vector de medias y $\Sigma$ la matriz de covarianzas.

El cálculo de esta expresión es un tanto complejo (Pinilla, 1995: 221), por tanto, si las bandas que conforman la imagen son estadísticamente independientes, la matriz de covarianzas resulta ser diagonal y ésta se forma con las varianzas dentro de cada banda. Mediante una transformación a componentes principales simplificamos el cálculo puesto que trabajamos con una combinación de bandas literalmente independientes (Vicentet alii, 1996: 29).

La función de densidad multivariante conforma una nube de puntos de probabilidad de ocurrencia de un suceso o cluster cuyo centro queda definido, respecto al origen, por el vector de medias y su forma por la matriz de covarianzas.

\section{DESARROLLO DE UN EJEMPLO}

Una vez formalizada la teoría que enmarca la definición de la imagen, así como la de la estruc- tura interna de la misma, veamos cómo se lleva a cabo la definición de clases de forma concreta. Tengamos en cuenta que nuestro objetivo final es la obtención de una imagen de tercer orden (calco), si bien presentamos un modelo general que trata de discriminar toda la variabilidad interna de la imagen. Es evidente, entonces, que la obtención de una máscara de la imagen (el calco) necesita de la separación precisa entre lo que es y no es pigmento.

Los cálculos que hemos presentado, así como los que veremos a continuación, han sido realizados por un ordenador con un software específico para estas tareas; por supuesto que el conocimiento teórico permite un uso correcto del mismo, ya que, generalmente, es necesario definir los parámetros que realizan los cálculos.

De la diversidad de métodos para efectuar el proceso de clasificación hemos optado por experimentar con aquellos orientados a maximizar la automatización. El procedimiento que presentamos a continuación consta de cuatro fases, a saber: 1. Entrenamiento del clasificador; 2. Asignación; 3. Contrastación de los resultados y 4. Presentación.

El proceso de clasificación de una imagen necesita de un conocimiento profundo de las características de las clases que formarán parte de la leyenda, de manera que el clasificador pueda asignar cada píxel de acuerdo con ella y de forma correcta.

Hemos elegido lo que habitualmente se conoce como método no supervisado en la bibliografía de teledetección espacial (Mather, 1987: 283; Lillesand y Kiefer, 1994: 604; Pinilla, 1995: 221).

El método no supervisado trata de agrupar $a u$ tomáticamente los datos de una imagen en determinado número de grupos homogéneos que respondan a la máxima similitud espectral de los mismos. En la fase de entrenamiento trataremos de definir una serie de áreas lo más homogéneas posibles, determinando sus características espectrales; medimos sus características de similaridad, o lo que es lo mismo, la distancia estadística entre los casos y, finalmente, aplicaremos algún criterio de agrupamiento.

Definidas las áreas de entrenamiento, se realiza un clustering con los píxeles de las mismas para determinar su agrupamiento natural. Si el resultado es suficientemente consistente se atribuye a cada cluster una clase y se asignan el resto de los píxeles. No obstante, debemos tener en cuenta que 
cada clase no proporciona un único valor de luminancia en cada banda, sino una distribución más o menos normal, de forma que necesitaremos asignarle como nivel digital, de esa banda y clase, el valor medio de los valores.

En cuanto a la separabilidad estadística de las clases, existen bastantes tipos de distancias. Entre las más utilizadas podemos citar la de Mahalanobis y la de Bhattachar que no vamos a definir aquí.

La fase de asignación no es sino la atribución de cada uno de los píxeles de la imagen a las categorías determinadas anteriormente con el método explicado. La forma de construir grupos consistentes se realiza mediante la definición de una función de similaridad que permitirá asegurar que un píxel concreto que pertenezca a un determinado cluster sea más parecido en sus características que cualquiera de los que pertenecen a otro.

El procedimiento será distinto dependiendo de la función de similaridad elegida por el algoritmo de agrupamiento. En nuestro caso hemos utilizado un método complejo que no es más que una aplicación de la teoría de decisión que hemos explicado anteriormente y se conode como clasificador de máxima probabilidad.

El fundamento del método es sencillo y su base matemática ha sido definida más arriba; veámoslo brevemente:

Un píxel que presente una luminancia $z$ tendrá una probabilidad determinada de pertenecer a la clase $w_{1}$ como sigue:

$$
p\left(z / w_{1}\right)=\frac{1}{\sigma_{1} \sqrt{2 \pi}} \exp \left[-\frac{1}{2}\left(\frac{z-\mu_{1}}{\sigma_{1}}\right)^{2}\right]
$$

siendo $\sigma_{1}$ y $\mu_{1}$ los parámetros que definen esa clase. Otra clase $w_{2}$ se calculará de la misma forma. Un píxel pertenece a la clase $w_{1}$ si y sólo si

$$
p\left(z / w_{1}\right) \geq p\left(z / w_{2}\right)
$$

Lo importante aquí es trazar la frontera entre una clase y otra, y ésta no es otra que la abscisa que pasa por la intersección de las dos funciones de densidad.

Si existen $n$ clases, se puede extender la condición a ellas y se considerará que $z \in w_{i}$ si

$$
p\left(z / w_{i}\right) \geq p\left(z / w_{j}\right) \forall j \neq i ; j=1, \ldots, n
$$

La aplicación de la teoría bayesiana, hemos visto, exige que un píxel se asigne a la clase que maximice la probabilidad a posteriori y como vimos, ésta, es función de las verosimilitudes y de las probabilidades a priori, en este caso, $z \in w_{i} \mathrm{y} z$ $\in w_{j} \mathrm{si}$

$$
p\left(z / w_{i}\right) p\left(w_{i}\right) \geq p\left(z / w_{j}\right) p\left(w_{j}\right) \quad \forall j \neq i ; j=1, \Lambda, n
$$

es decir, que sea máximo el producto de la probabilidad de que un píxel, con valor $z$, pertenezca a una clase por la probabilidad de que cualquier otro píxel pueda pertenecer a dicha clase desde la información que se tiene a priori sobre la clase en cuestión.

La extensión a varias bandas (Pinilla, 1995: 241), sería

$$
p\left(\vec{z} / w_{i}\right) p\left(w_{i}\right) \geq p\left(\vec{z} / w_{j}\right) p\left(w_{j}\right) \quad \forall j \neq i ; j=1, \ldots, n
$$

El problema principal, una vez realizados los cálculos y la subsecuente clasificación de la imagen, es la de la verificación de los resultados. Los errores en la clasificación pueden ser de dos tipos:

a. Error tipo I (de omisión), se produce cuando un píxel, perteneciendo a una categoría, no es asignado a ella.

b. Error tipo II (de comisión), se produce cuando un píxel, no perteneciendo a una categoría, es asignado a ella.

El mayor problema que presentan las imágenes de arte rupestre en la fase de asignación se debe a la existencia de una enorme fragmentación de la información, lo que aumenta considerablemente la existencia de píxeles mixtos, llamados también píxeles de borde, es decir, aquellos que pueden pertenecer a más de una categoría. En esencia, la cuestión se debe a la existencia, en muchos casos, de un bajo contraste espectral en áreas contiguas.

No debemos olvidar el papel que juega la definición de la leyenda, ya que, si ésta es muy genérica tendremos tasas de error muy bajas, aunque obtendremos menos información. Si la leyenda es muy amplia, obtendremos errores de asignación altos, si bien el volumen de información será mayor. Es aquí donde la definición de los objetivos influye más, ya que dependiendo de lo que deseamos obtener así será elegida una leyenda concreta.

La contrastación definitiva entre los píxeles asignados por el clasificador y la naturaleza real de cada uno de ellos se realiza mediante lo que llamamos matriz de confusión, un producto típico del software encargado de realizar operaciones de clasificación y que no vamos a describir aquí, puesto que sus resultados dependen ya del caso

T. P., 55, n. $^{\circ} 1,1998$ 

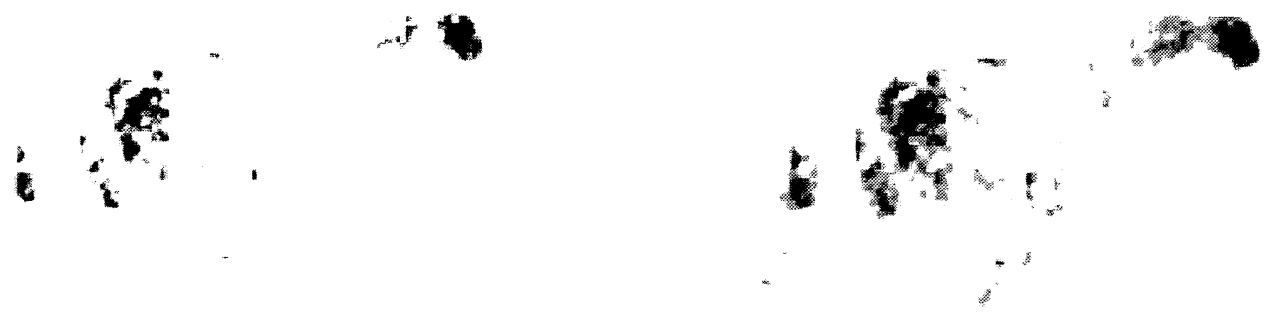

a) clases 1-2

b) clases 1-3

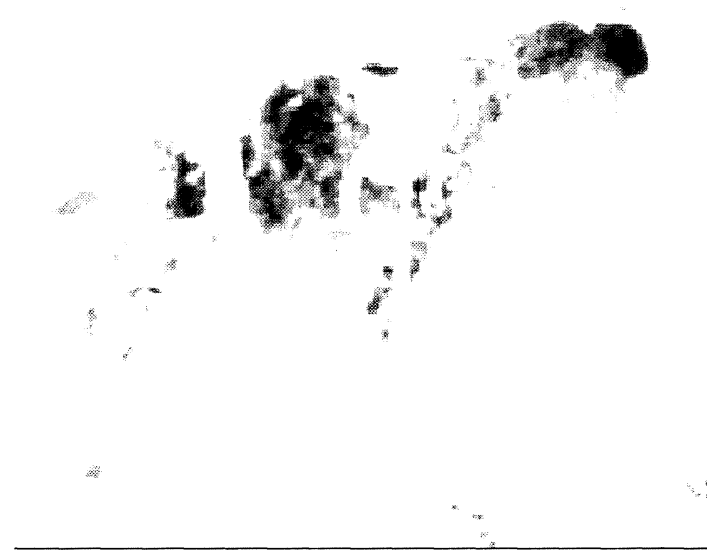

c) clases $1-4$
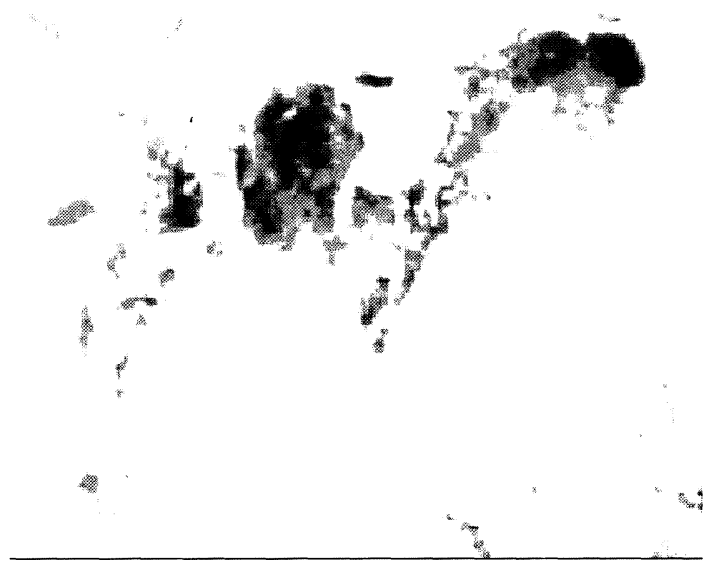

d) clases 1-5
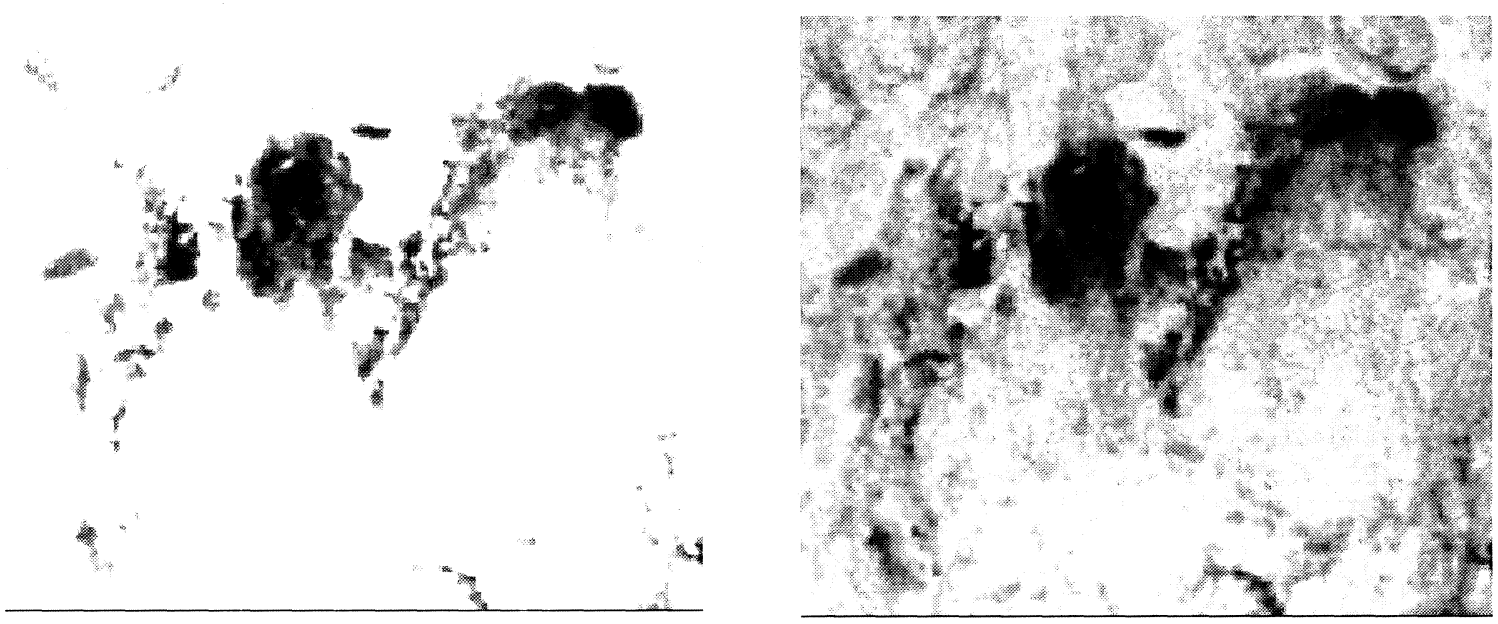

e) clases 1-6

f) todas las clases (1-10)

Fig. 6. Clasificación de la imagen de la lámina I y representación aditiva de las clases de pigmento: a) clases 1 y 2; b) clases 1-3; c) clases 1-4; d) clases 1-5; e) clases 1-6; f) clasificación general de la figura. 


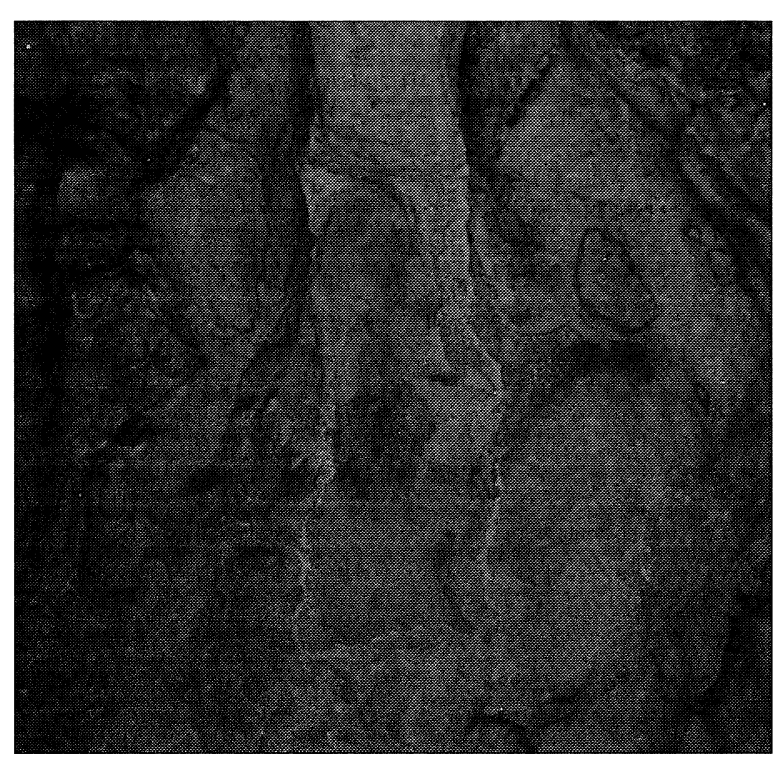

Lám. I. Figura 1bis (Abrigo III), Abrigos de la Saltadora, Barranco de la Valltorta, Cuevas de Vinromá, Castellón. Tamaño figura $9 \mathrm{cms}$. Fotografía tomada en octubre de 1973 (CPRL del Departamento de Prehistoria del C.E.H.). Figura identificada como posible cierva a derecha. No existe calco de la misma en la publicación de Ripoll (1970).

concreto clasificado (Pinilla, 1995: 251-255; Mather, 1987: 324-328).

En nuestro caso, hemos elegido para presentar el trabajo una imagen compleja, donde la identificación final de la forma se ve condicionada por la necesidad de una discriminación selectiva de la información suministrada por la clasificación (Lám. I). Se ha procesado mediante el módulo de clasificación automática del software de proceso de imagen ER-MAPPER. Se ha seguido el proceso descrito alimentando el programa con los parámetros oportunos. El primer resultado que se consiguió fue la figura $6 \mathrm{f}$ en la que se observa la categorización general realizada. La agregación de cada una de las clases establecidas para el pigmento de la imagen nos acerca progresivamente a la definición de la figura (una cierva en posición de alerta), indicándonos el distinto grado de conservación de cada uno de ellos. A partir de la clase 5 (Fig. 6d) aparecen zonas de pigmento lavado que distorsionan la forma original, especialmente en la cabeza, zona que queda bien definida con las tres primeras clases (Fig. 6b). Por último las patas traseras se muestran con cierta claridad a partir de la clase 6 (Fig. 6e), pero esos valores empiezan a confundirse con zonas de relieve ajenas a la propia figura.

En conclusión, podemos decir que el método es bastante sencillo de conceptualizar y fácil de implementar informáticamente, de modo que la realización de calcos se automatiza lo suficiente como para emprender la tarea de realizar el trabajo de calcado electrónico de una gran cantidad de imágenes. Tarea ésta necesaria para completar la documentación del CPRL, en el que una cantidad de figuras carecen de ellos, y otras sólo cuentan con copia de calcos antiguos, cuya escasa fiabilidad ya se ha comentado.

\section{BIBLIOGRAFÍA}

Almagro Basch, M. y Almagro Gorbea, M. (1968): Estudios de arte rupestre nubio. I. Yacimientos situados en la orilla oriental del Nilo, entre Nag Kolorodna y Kars Ibrim (Nubia egipcia). Memorias de la Misión Arqueológica Española en Egipto y Nubia, X. Madrid.

ArCÀ, A. (1997): "Slide scanning for a digital archive". Tracce. On line Rock Art Bulletin, 8. (http:// www. $10 \mathrm{mb} . c 0 \mathrm{~m} / \mathrm{rupestre/tracce/sliscom.html).}$

Aujoulat, N. (1987): Le relevé des oeuvres pariétales paléolithiques. Enregistrement et traitement des données. Documents d'Archéologie Française, 9. Editions de la Maison des Sciences de 1'Homme. Paris.

BeDNARIK, R.G. (1995): "Perpetual digital preservation of rock art imagery". International Newsletter on Rock Art, 12: 25-27.

BedNARIK, R.G. y SeshadRI, K. (1995): "Digital colour reconstitution in rock art photography". Rock Art Research, 12 (1): 42-51.

Bell, J.; Jerôme, J-P.; Sawyer, P.; Magar, V. y Price, N.S. (1996): "Stereophotogrammetric recording of rock art at the Cueva de El Ratón, Baja California, Mexico". ICOM Committee for Conservation. 11th Triennial Meeting Preprints. Edinburgh, 1996. James \& James Ltd. London: 454-57.

Beltrán, A. (1981): "Métodos del trabajo sobre el terreno en el arte rupestre". Caesaraugusta, 53-54: 133-137.

Carrasco, J. y Pastor, M. (1981): "Avance al estudio de las pinturas rupestres esquématicas de la cueva del Plato. Panel 'A' (Otiñar, Jaén)". Zephyrus, XXXIIXXXIII: 167-180.

Castelo Branco, R.M.G. (1997): "Computer techniques applied to rock art in NE Brasil: the Lagoa das PedrasForquilha archaeological site". Tracce. On line Rock Art Bulletin, 9. (http://www.10mb.com/rupestre/ tracce/comptecn.html) 
DurÁn i SANPERe, A. (1915-20): "Exploració arqueológica del Barranc de La Valltorta. Les pintures rupestres". Anuari de l'Institut d'Estudis Catalans, 6: 444454.

Hernández Pacheco, E. (1919): "Problema y métodos de estudio del arte rupestre". Boletín de la Real Sociedad Española de Historia Natural, XIX: 407-418.

- (1924): Las pinturas prehistóricas de las cuevas de La Araña (Valencia). Comisión de Investigaciones Paleontológicas y Prehistóricas, 34. Madrid.

Kambouris, A.A. (1995): "The development and use of digital technology in the preservation of the photographic archives at the British School at Athens". Archaeological Computing Newsletter, 42: 5-11.

KüHN, H. (1926): "Die materien der Valltorta-Schlucht, Provinz Castellón". IPEK. Jahrbuch für prähistorische und ethnographische Kunst: 33-45.

Lillesand, T.M. y Kiefer, R.W (1994): Remote Sensing and Image interpretation. John Willey and Sons, New York.

LOUBSER, J.H.N. (1997): “The use of Harris diagrams in recording, conserving and interpreting rock paintings". International Newsletter on Rock Art, 18: 14-21.

Llanos, A. y García, F.J. (1981): "Levantamiento fotogramétrico del techo de la sala de las pinturas de la cueva de Altamira". Altamira Symposium. Ministerio de Cultura. Madrid: 591-611.

MATHER, P.M. (1991): Computer processing of Remotelysensed Images. John Willey and Sons. Chichester.

Moliner, M ${ }^{\text {a }}$ (1992) Diccionario de uso del Español. Editorial Gredos. Madrid.

Moneva, Ma D. (1993): "Primeros sistemas de reproducción de arte rupestre en España". Espacio, Tiempo y Forma. Serie I, 6: 413-441.

Moreno, T. (1996): El color. Historia, teoría y aplicaciones. Editorial Ariel, S.A. Barcelona.

Peña, D. (1986): Estadística, modelos y métodos. 1. Fundamentos. Alianza Universidad Textos, 109. Alianza Editorial. Madrid.
Pinilla, C. (1995): Elementos de Teledetección. RA-MA. Madrid.

Obermaier, H. y Wernet, P. (1919): Las pinturas rupestres del Barranco de Valltorta (Castellón). Comisión de Investigaciones Paleontológicas y Prehistóricas, 23. Madrid.

OrMEÑo, S. (1993): Teledetección fundamental. Escuela Universitaria de Ingeniería Técnica Topográfica. Universidad Politécnica de Madrid. Madrid.

Ripoll, E. (1970): "Noticia sobre l'estudi de les pintures rupestres de 'La Saltadora' (Barranc de La Valltorta, Castellón)". Cuadernos de Arqueología e Historia de la Ciudad, XIV: 9-24.

SANCHIDRIÁN, J.L. (1987): "Reproducción del arte rupestre". "Arte Rupestre en España”. Revista de Arqueología (monografía): 123-125.

Vertut, J. (1981): "Contribution des techniques photographiques a l'etude et a la conservation de l'art prehistorique". Altamira Symposium. Ministerio de Cultura. Madrid: 661-675.

ViCENT, J.M. (1994): "La digitalización del archivo de arte rupestre post-paleolítico del Departamento de Prehistoria del Centro de Estudios Históricos (C.S.I.C.), Madrid". Boletín del Instituto Andaluz de Patrimonio, 7: 41-43.

Vicent, J.M.; Montero, I.; Rodríguez Alcalde, A.L.; Martínez Navarrete, Ma I. y Chapa, T. (1996): "Aplicación de la imagen multiespectral al estudio y conservación del arte rupestre postpaleolítico". Trabajos de Prehistoria, 53 (2): 19-35.

Vicent, J.M.; Montero, I. y Rodríguez Alcalde, A.L. (1997): "Digital image processing and prehistoric art. The digitalizing of the rock art archives of the Departamento de Prehistoria (Centro de Estudios Históricos, CSIC)". Tracce. On line Rock Art Bulletin, 8. (http://www.geocities.com/Athens/3857/ levant.html).

VIÑAS, R. (dir.) (1982): La Valltorta. Arte rupestre del Levante español. Ediciones Castell, S.A. 